\title{
ADHERENCE TO INSULIN TREATMENT IN CHILDREN WITH TYPE I DIABETES MELLITUS AT A HOSPITAL IN MALAYSIA
}

\author{
CHONG LAI YING, NORAIDA MOHAMED SHAH* \\ Faculty of Pharmacy, Universiti Kebangsaan Malaysia, Jalan Raja Muda Abdul Aziz, 50300 Kuala Lumpur, Malaysia. \\ Email: noraida_mshah@ukm.edu.my
}

Received: 20 May 2017, Revised and Accepted: 09 August 2017

\section{ABSTRACT}

Objective: This study aimed to evaluate adherence to insulin treatment and identify factors that influence adherence in children with Type 1 diabetes mellitus (T1DM) at a tertiary care hospital in Malaysia.

Methods: Patients were identified from the pharmacy computer system based on the prescribed insulin therapy from 2010 to 2014 . Medical records of screened patients were then retrieved from the medical record department. Adherence was assessed through the medication possession ratio (MPR) and glycated hemoglobin A1c value. Patients were classified as adherent or non-adherent if the MPR calculated for the prescribed insulin regimen was $\geq 80 \%$ or $<80 \%$, respectively. Patients with A1c values $<7.5 \%$ based on medical records were also classified as adherent.

Results: A total of 57 patients were included in this study, with a $57.9 \%$ of male predominance and a mean age of $14.39 \pm 3.41$ years. $39(68.4 \%)$ and three patients (5.3\%) were classified as adherent to insulin treatment according to MPR and A1c values, respectively. Poor agreement between the MPR and A1c value in determining adherence was found based on kappa analysis (kappa $=-0.108, p=0.009$ ). There was no association between age, sex, race, presence of comorbidities, or duration of T1DM diagnosed and adherence based on the A1c value ( $>0.05$ ). These predictors were also found to be insignificant based on multiple logistic regression analysis $(\mathrm{p}>0.05)$.

Conclusion: Adherence to insulin treatment based on the A1c measurement was generally poor among children with T1DM. Further, prospective research should be performed in this area to identify reasons for the non-adherence to insulin treatment so that appropriate interventions can be instituted to improve adherence and ultimately prevent complications from the disease.

Keywords: Adherence, Children, Malaysia, Type I diabetes mellitus.

(C) 2017 The Authors. Published by Innovare Academic Sciences Pvt Ltd. This is an open access article under the CC BY license (http://creativecommons. org/licenses/by/4. 0/) DOI: http://dx.doi.org/10.22159/ajpcr.2017.v10i11.20130

\section{INTRODUCTION}

The incidence rate of Type 1 diabetes mellitus (T1DM) in children is increasing. According to the International Diabetes Federation, of the estimated 542,000 prevalent cases of childhood (age <15 years) T1DM worldwide, $15 \%$ are from Southeast Asia [1]. Insulin is the life-saving treatment for T1DM [1]. However, the rate of adherence to insulin treatment among children with T1DM in the Western Pacific Region has not yet reached a satisfactory level, with a mean glycated hemoglobin A1c value of $8.8 \%$ [2].

Adherence to insulin treatment is an issue among children with T1DM, as poor adherence has been associated with poor clinical outcomes [3,4]. In a review by Walker [3], frequent hospitalizations and emergency department visits among children and adolescents with chronic diseases, such as T1DM, may be because of poor medication adherence. In addition, another review also reported that children with T1DM who had less than optimal adherence to the diabetes regimen had poorer glycemic control, increased morbidity, medical and psychological complications, increased hospitalizations and clinic visits, and increased mortality [4].

Early identification of children with T1DM at a heightened risk for nonadherence to insulin medications could probably allow for intervention to prevent or reduce non-adherence among them [4]. Chang et al. studied non-adherence behavior (mean of A1c $=10.26 \%$ ) but not the factors influencing adherence in Taiwanese children and adolescents with T1DM [5]. Young children with T1DM adhered better to insulin treatment with better maternal diabetes knowledge, shorter duration of disease, and younger age [6]. A review by Schwartz et al. revealed that adolescents with T1DM between the age of 13 and 15 years, females with depression and eating disorders, and males with behavior and learning problems were at risk for non-adherence among pediatric patients with T1DM [4].

A review on medication adherence by Brown and Bussell stated that measurement of medication adherence was challenging because adherence was an individual patient behavior. Subjective measurements obtained by asking patients, family members, caregivers, and physicians about the patient's medication use and objective measurement obtained by counting pills, examining pharmacy refill records, or using electronic medication event monitoring systems have been used to assess adherence to medications [7].

To the best of our knowledge, there has been published research on the effects of ethnicity in Malaysia and factors (quality of life, depression, and family problem) associated with diabetic control among young adults and adolescents with T1DM, but the factors that influence medication adherence were not covered in that study [8]. The primary aim of this study was to evaluate adherence to insulin treatment and to identify factors that influence adherence behaviors in children with T1DM at Universiti Kebangsaan Malaysia Medical Center (UKMMC). In this study, the suitability of medication possession ratio (MPR) was evaluated by comparison with the gold standard of A1c, the predictor of glycemic control. In addition, demographic data of age, sex, and race, together with clinical data, for example, the presence of comorbidities and duration of time since diabetes diagnosis, were assessed to reveal predictors of adherence among patients with T1DM at UKMMC. 


\section{METHODS}

This study was a non-experimental, retrospective study conducted at the UKMMC. This study recruited pediatric patients with T1DM who made outpatient visits at Clinic Pediatric 1 UKMMC from 2010 to 2014. Patients were identified from the pharmacy computer system based on prescribed insulin therapy. The medical records of the screened patients were then retrieved from the medical record department. The latest complete 1-year patient visit records and laboratory results were used for this study.

\section{Patient selection criteria}

Pediatric patients $\leq 18$ years old based on the study period with a primary diagnosis of T1DM according to medical records and a history of T1DM for at least 1 year were included in this study. They had to have a complete year of patient visit records and laboratory results from 2010 to 2014 and obtain medications from the outpatient pharmacy. Patients must have taken at least one of the following insulin prescriptions at UKMMC (based on UKMMC drug formulary 2014): Insulin aspart (Novorapid ${ }^{\circledR}$ ), insulin lispro (Humalog ${ }^{\circledR}$ ), soluble insulin (Actrapid $\mathrm{HM}^{\circledR}$ ), isophane insulin (Insulatard $\mathrm{HM}^{\circledR}$ ), insulin glargine (Lantus $^{\circledR}$ ), insulin detemir (Levemir ${ }^{\circledR}$ ), 30\% soluble insulin and 70\% isophane insulin (Mixtard $30^{\circledR}$ ), or $30 \%$ soluble insulin and $70 \%$ insulin as part protamine crystals (Novomix $30^{\circledR}$ ). Patients taking a dose of insulin which is altered based on the diet intake and blood glucose level were excluded from this study.

\section{Sampling methods}

Convenience sampling techniques were used in the patient selection process. Data collection was divided into two phases, dispensing data and laboratory results, which was conducted in the outpatient pharmacy department followed by medical record data, which was performed in the medical record department at UKMMC.

\section{Ethical approval}

This study was reviewed and approved by the Research Ethics Committee, UKM, with ethical approval number UKM 1.5.3.5/244/NF023-14.

\section{Research instrument}

\section{Patient's medical records}

Demographic data and clinical data were collected and recorded in a data collection form. Demographic data included patient registration number, date of birth, age, sex, and race. Clinical data obtained included the date of disease diagnosis, duration of disease, presence of comorbidity, and history of hospitalization. A1c values were obtained from medical records.

Data collection for the screened patients from the pharmacy computer system was based on the prescribed insulin therapy according to the Drug Formulary UKMMC 2014. The prescribed insulins are listed in the inclusion criteria.

\section{Refill medication record}

Using the pharmacy computer system, the latest complete 1-year patient visit record from 2010 to 2014 was recorded in a data collection form to evaluate the medication adherence through MPR. MPR equals the total number of days of supply for all claims during the study period divided by a total number of days elapsed during the period. The time period used in the denominator for this calculation is length of therapy, which was the number of days that elapsed between the fill date of the first and last prescription during the study period, and the numerator was defined as the days of supply for all claims before the final fill date [9]. In this study, the number of insulin pens or cartridges being supplied was not stated in the pharmacy database. Therefore, the duration of supply was assumed to be the days of supply for all claims before the final fill date. In addition, the dose of insulin prescribed in the refill medication record was recorded and used for the analysis to calculate the adherence rate.

\section{Adherence measure}

Adherence to insulin treatment was assessed through MPR and A1c value. Patients were classified as non-adherent, if the MPR calculated for the prescribed insulin regimen was $<80 \%$, and as adherent, if it was $\geq 80$ [10]. The last A1c value during the study period was used to indicate adherence among diabetic patients. Patients with $\mathrm{A} 1 \mathrm{c}$ values $<7.5 \%$ based on medical records were classified as adherent [11]. This target was same as the newly set A1c target value for children with T1DM in the American Diabetes Association guidelines [12].

\section{Final outcome measure}

Due to the problem of overestimating adherence when using MPR, A1c values were used as the final adherence measure.

\section{Statistical analysis}

SPSS $^{\circledR}$ version 22 was used to analyze the collected data. Descriptive statistics were used to report the baseline characteristics of age, sex, race, comorbidities, duration of T1DM, type of combination insulin prescribed, and change in insulin dose.

Adherence to insulin treatment was assessed by MPR and A1c value. Level of agreement between MPR and A1c value in determining adherence was assessed by kappa analysis. Interpretations of kappa values are shown in Appendix Table 1. Associations of categorical demographic data and clinical data with adherence level were analyzed by Fisher's exact test because of an expected frequency $<5$. Associations of age and duration of disease diagnosis with adherence level were analyzed using Mann-Whitney U-test. Multiple logistic regression analysis was used to analyze factors associated with non-adherence using A1c measurement as an outcome. All reported $p$ values were calculated using two-sided tails, with $\mathrm{p}<0.05$ was considered statistically significant. The confidence level was set at $95 \%$.

\section{RESULTS}

\section{Patient characteristics}

A total of 161 subjects from the Pediatric Clinic (Endocrine) were identified using the UKMMC pharmacy database based on their insulin prescription. Among 161 subjects, only 92 subjects fulfilled the inclusion criteria. Of these, another 35 subjects were excluded from this study, 11 subjects with unavailable files, 15 subjects with T1DM not being their primary diagnosis, and nine subjects who switched medications during the study period. Ultimately, only 57 subjects were recruited in this study.

Demographic and clinical characteristics are summarized in Table 1. A total of 57 patients were included in this study, with a $57.9 \%$ of male predominance and mean age of $14.39 \pm 3.41$ years. The study population included Chinese participants (52.6\%), followed by Malay (35.1\%), Indian (10.5\%), and other participants (1.8\%). Many of them (70.2\%) had no associated comorbidities and had a mean disease duration of $8.05 \pm 3.83$ years. The most common combination insulin prescribed was insulin aspart penfill + insulin glargine, which was prescribed to $45.6 \%$ of participants, while both combination of insulin aspart penfill + insulin detemir (15.8\%) and combination of insulin aspart flexpen + insulin glargine (15.8\%) were also popular combinations of insulin prescribed in UKMMC.

\section{Prevalence of non-adherence}

In this study, adherence was assessed through MPR and A1c value. Patients were classified as non-adherent if the MPR calculated for the prescribed insulin regimen was $<80 \%$ and the latest A1c value based on medical record was $>7.5 \%$. The prevalences of non-adherence to insulin treatment using the two methods were different (Table 2). $39(68.4 \%)$ and three patients (5.3\%) were classified as adherent to the insulin treatment according to MPR and A1c value, respectively.

By assessing demographic factors, patients who were non-adherent according to A1c value were more commonly male (57.4\%) and Chinese (51.9\%). For clinical factors, patients without comorbidities had the 
Table 1: Characteristics of study sample

\begin{tabular}{ll}
\hline Characteristics (n=57) & Frequency n (\%) \\
\hline Age & \\
Gender & \\
Female & $24.39 \pm 3.41$ \\
Male & $33(57.9)$ \\
Race & \\
Malay & $24(42.1)$ \\
Chinese & $33(57.9)$ \\
Indian & $6(10.5)$ \\
Others & $1(1.8)$ \\
Comorbidities & $12(29.8)$ \\
Yes & $40(70.2)$ \\
No & \\
Duration of Type I diabetes mellitus (years) & \\
Number of insulin prescribed & \\
Type of combination insulin prescribed & \\
Insulin aspart penfill + insulin glargine & $26(45.6)$ \\
Insulin aspart penfill + insulin detemir & $9(15.8)$ \\
Insulin aspart flexpen + insulin glargine & $9(15.8)$ \\
Insulin lispro kwikpen + insulin glargine & $3(5.3)$ \\
Insulin aspart penfill only & $3(5.3)$ \\
Insulin aspart flexpen + insulin detemir & $2(3.5)$ \\
Insulin aspart penfill + soluble insulin penfill + insulin glargine & $1(1.8)$ \\
Insulin aspart flexpen + soluble insulin penfill + insulin detemir & $1(1.8)$ \\
30\% soluble insulin and 70\% isophane insulin flexpen & $1(1.8)$ \\
Soluble insulin + isophane insulin & $1(1.8)$ \\
Insulin aspart flexpen + insulin glargine + isophane insulin & $1(1.8)$ \\
Adjustment in insulin dose & \\
Yes & $40(70.2)$ \\
No & $17(29.85)$ \\
\hline
\end{tabular}

SD: Standard deviation

highest rate of non-adherence, which was $72.2 \%$. Patients prescribed with insulin aspart penfill + insulin glargine had the highest rate of nonadherence (46.3\%), and $70.4 \%$ of patients with adjustments in insulin dose were non-adherent.

Level of agreement in between adherence values calculated using MPR and A1c value

The level of agreement in adherence values calculated using MPR and A1c value was statistically significant $(\mathrm{p}=0.009)$, with kappa value of -0.108 , showing poor agreement between adherence measured using MPR and that measured using A1c value (Table 3).

\section{Association between demographic factors and adherence level}

Fisher's exact test was used to correlate the demographic factors sex and race with the adherence. The Mann-Whitney U-test was used to compare mean age between the non-adherence group and adherence group. Sex and race were not associated with adherence. There was also no evidence to support a correlation between adherence and age $(p=0.339)$. The summary of associations between demographic factors and adherence level is presented in Table 4.

\section{Association between clinical factors and adherence level}

Analysis by Fisher's exact test revealed that poor adherence was not associated with any clinical factors, including comorbidities, type of combination insulin prescribed, and adjustment of insulin. There was also no association between duration of disease and adherence by Whitney U-test $(\mathrm{p}=0.844)$. A summary of associations between clinical factors and adherence level is shown in Table 5.

\section{Predictors of poor adherence}

A full model of multiple logistic regressions was created to measure relationships between age, sex, race, comorbidities, and duration of disease and adherence, using A1c value. Analysis data from the regression model suggested that age, sex, and race factors were not predictors of poor adherence. In other words, the null hypotheses were not rejected. Similarly, no clinical factors, including comorbidities and
Table 2: Adherence level using two different methods

\begin{tabular}{llll}
\hline \multirow{2}{*}{$\begin{array}{l}\text { Adherence } \\
\text { measure }\end{array}$} & \multicolumn{2}{l}{ Adherence level, $\mathbf{n}(\%)$} & Mean \pm SD \\
\cline { 2 - 3 } & Good (\%) & Poor (\%) & \\
\hline MPR & $39(68.4)$ & $18(31.6)$ & $9.707 \pm 1.844$ \\
A1c & $3(5.3)$ & $54(94.7)$ & \\
\hline
\end{tabular}

SD: Standard deviation, MPR: Medication possession ratio

Table 3: Level of agreement between adherence using MPR and $\mathrm{A1c}$

\begin{tabular}{llll}
\hline & Value & $\begin{array}{l}\text { Standard } \\
\text { error }\end{array}$ & p value \\
\hline Measurement of agreement (kappa) & -0.108 & 0.062 & $0.009 *$ \\
\hline Kappa analysis, * ${ }^{*}<0.05$. MPR: Medication possession ratio &
\end{tabular}

Table 4: Association between demographic factors and adherence level based on A1c

\begin{tabular}{llll}
\hline Factor & \multicolumn{2}{l}{ Adherence level } & p value \\
\cline { 2 - 3 } & $\begin{array}{l}\text { Good } \\
\mathbf{n = 3}(\%)\end{array}$ & $\begin{array}{l}\text { Poor } \\
\mathbf{n = 5 4}(\%)\end{array}$ & \\
\hline $\begin{array}{l}\text { Age (years) } \\
\text { Gender }\end{array}$ & $3(5.3)$ & $54(94.7)$ & $0.339^{*}$ \\
Female & $1(33.3)$ & $23(42.6)$ & \multirow{2}{*}{1.000} \\
Male & $2(66.7)$ & $31(57.4)$ & \\
Race & $1(33.3)$ & $19(35.2)$ & 1.000 \\
Malaysian & $2(66.7)$ & $28(51.9)$ & \\
Chinese & $0(0.0)$ & $6(11.1)$ & \\
India & $0(0.0)$ & $1(1.9)$ & \\
Others & & & \\
\hline
\end{tabular}

Fisher's exact test, $\mathrm{p}<0.05 .{ }^{*} \mathrm{p}$ value of age is analyzed using Mann-Whitney U-test 
duration of disease, significantly correlated with adherence measures. All analysis using multiple logistic regression is summarized in Table 6.

\section{DISCUSSION}

Prevalence of non-adherence

Adherence can be defined as "the extent to which patients follow through decisions about medicine taking" [13]. In this study, investigating the adherence rate to insulin treatment among children, the adherence rate was poor among children with T1DM. A total of $54(94.7 \%)$ subjects had A1c values $>7.5 \%$, which was considered nonadherence to insulin treatment. Craig et al. [2] also found a poor rate of adherence among children with T1DM, with a mean non-adherence rate of $8.8 \pm 1.9 \%$, using A1c value. A meta-analysis by Hood et al. examining the association between glycemic control and adherence to treatment among pediatric patients with T1DM concluded that when adherence increased, A1c values decreased [14]. Compliance problems among adolescents with T1DM were associated with poor glycemic control when the threshold was stricter (A1c $\leq 8 \%$ ). However, compliance problems were not associated with poor glycemic control when the A1c threshold value was $10 \%$. This suggested that different definitions of diabetic control may affect the association between studied factors and level of glycemic control [8].
Level of agreement between adherence values calculated using MPR and A1c value

The kappa value of $-0.108(\mathrm{p}=0.009)$ showed statistically significant, but poor agreement in determining adherence measured using MPR and $\mathrm{A} 1 \mathrm{c}$ value. This study proved that both variables were independent variables, and adherence cannot only be calculated using MPR. If the MPR value suggested adherence to insulin medication, this did notimply that the A1c value also suggested adherence to insulin medication. A1c measurement was the gold standard of measuring glycemic control [15]. $39(68.4 \%)$ and three patients (5.3\%) were classified as adherent to insulin treatment according to the MPR and A1c values, respectively. Since the number of pens or cartridges being supplied was not stated in the pharmacy database, the duration of supply was used to assume to be the total days of supply, which may have been an overestimation. As such, the adherence to insulin treatment may be higher than the calculated value.

Laboratory tests are guides for diagnosis, decision-making in treatment, monitoring, and baseline health evaluation [16]. Hemoglobin A1c helps in the management of patients with diabetes, as it reflects the past 3 months of blood glucose concentrations in the blood compared to blood sugar measurements that only reflect the conditions at

Table 5: Association between clinical factors and adherence level based on A1c

\begin{tabular}{|c|c|c|c|c|}
\hline \multirow[t]{2}{*}{ Factor } & \multicolumn{2}{|c|}{ Adherence level } & \multirow[t]{2}{*}{$\chi^{2}$ value } & \multirow[t]{2}{*}{ p value } \\
\hline & $\begin{array}{l}\text { Good } \\
n=3(\%)\end{array}$ & $\begin{array}{l}\text { Poor } \\
n=54(\%)\end{array}$ & & \\
\hline Comorbidities & & & & $0.209^{\#}$ \\
\hline Yes & $2(66.7)$ & $15(27.8)$ & & \\
\hline No & $1(33.3)$ & $39(72.2)$ & & \\
\hline Duration of Type I diabetes mellitus (years) & $3(5.3)$ & $54(94.7)$ & & $0.844^{*}$ \\
\hline Type of combination insulin prescribed & & & 15.575 & $0.171^{\#}$ \\
\hline Insulin aspart penfill + insulin glargine & $1(33.3)$ & $25(46.3)$ & & \\
\hline Insulin aspart penfill + insulin detemir & $0(0.0)$ & $9(16.7)$ & & \\
\hline Insulin lispro kwikpen + insulin glargine & $1(33.3)$ & $2(3.7)$ & & \\
\hline Insulin aspart penfill only & $0(0.0)$ & $3(5.6)$ & & \\
\hline Insulin aspart flexpen + insulin detemir & $1(33.3)$ & $1(1.9)$ & & \\
\hline Insulin aspart flexpen + insulin glargine & $0(0.0)$ & $9(16.7)$ & & \\
\hline Insulin aspart penfill + soluble insulin penfill + insulin glargine & $0(0.0)$ & $1(1.9)$ & & \\
\hline Insulin aspart flexpen + soluble insulin penfill + insulin detemir & $0(0.0)$ & $1(1.9)$ & & \\
\hline Insulin aspart flexpen + insulin glargine + isophane insulin & $0(0.0)$ & $1(1.9)$ & & \\
\hline Adjustment in insulin dose & & & & $1.000^{\#}$ \\
\hline Yes & $2(66.7)$ & $38(70.4)$ & & \\
\hline No & $1(33.3)$ & $16(29.6)$ & & \\
\hline
\end{tabular}

Table 6: Relationship of demographic/clinical factors with adherence using A1c

\begin{tabular}{|c|c|c|c|c|c|c|}
\hline \multirow[t]{2}{*}{ Demographic/clinical factors } & \multirow[t]{2}{*}{$B$ value } & \multirow[t]{2}{*}{ Standard error } & \multirow[t]{2}{*}{ p value } & \multirow[t]{2}{*}{ Odds ratio } & \multicolumn{2}{|c|}{$95 \% \mathrm{CI}$} \\
\hline & & & & & Lower & Upper \\
\hline Age (years) & -0.435 & 0.435 & 0.338 & 0.647 & 0.266 & 1.574 \\
\hline \multicolumn{7}{|l|}{ Gender } \\
\hline \multicolumn{7}{|l|}{ Female (reference) } \\
\hline Male & -0.861 & 1.438 & 0.550 & 0.423 & 0.025 & 7.087 \\
\hline Race & & & 0.992 & & & \\
\hline Chinese & -0.441 & 1.419 & 0.756 & 0.644 & 0.040 & 10.384 \\
\hline Indian & 17.571 & 15487.027 & 0.999 & 42763254.47 & 0.000 & \\
\hline Others & 15.185 & 40192.970 & 1.000 & 3934138.590 & 0.000 & \\
\hline \multicolumn{7}{|l|}{ Comorbidities } \\
\hline \multicolumn{7}{|l|}{ Yes (reference) } \\
\hline No & 2.114 & 1.423 & 0.137 & 8.278 & 0.509 & 134.529 \\
\hline Duration of Type I & 0.026 & 0.209 & 0.903 & 1.026 & 0.681 & 1.545 \\
\hline Diabetes mellitus (years) & & & & & & \\
\hline
\end{tabular}


certain time [16,17]. Adherence assessment based on the MPR has its limitations, as it is not suitable for short time intervals and requires at least 1 year of patient visitation records [18]. Even though in this study, MPR was not suitable for determining insulin adherence, one study proved that MPR was a suitable measure for adherence assessment in patients taking oral antihyperglycemic drugs, antihypertensive drugs, and lipid-lowering medications [18].

\section{Associations between demographic factors and adherence}

Age, sex, and race were not associated with adherence. There was also no association between sex and treatment adherence in young children with T1DM in a Scottish diabetic clinic [6]. Assessing demographic factors may reveal particular patients with high risk of poor adherence. Several studies showed that non-adherence mostly occurred in adolescence. There was an association in adolescents aged between 13 and 18 years and poor glycemic control [15]. A study performed by Grey et al. suggested that continuing parenteral support and guidance appeared to help adolescents with T1DM achieve success in metabolic control over 1 year of follow-up [19]. Davis et al. found that parental warmth was associated with better adherence rates in children with T1DM, aged 4-10 years [20]. Onset of puberty with physical growth and metabolic fluctuation makes it difficult for adolescents to control their blood glucose levels. Furthermore, in this developmental phase, they tended to conceal presence of the disease, and peer pressure made them more susceptible to the poor adherence [21]. Insulin resistance because of physiological changes during puberty in adolescence and developmental behaviors present barriers to adherence [22].

\section{Association between clinical factors and adherence}

The combination of insulin prescribed, presence of comorbidities, and adjustment of insulin dose were not significantly related to insulin adherence according to the analysis by Fisher's exact test. The duration of disease diagnosis by Mann-Whitney U-test was also not shown to associate with adherence to insulin treatment. This finding was contradictory to the study performed by Krapek et al. They discovered an association between duration of disease and A1c value $(p=0.026)$. In that study, there was a noticeable increase in A1c value with approximately 5-10 years of disease duration. In addition, Krapek et al. also found that there was no association with A1c value in patients taking insulin, but those patients with insulincontaining regimens tended to have higher A1c values [23]. Hilliard et al. concluded that adolescents, aged between 13 and 18 years, with poor glycemic control more commonly had longer disease durations and comorbidities [15].

\section{Effect of non-adherence}

Non-adherence to insulin treatment in children with T1DM at UKMMC was the highlighted issue in this study. We are concerned that nonadherence would lead to increased occurrence of diabetic ketoacidosis, a common cause of death associated with diabetes in childhood [24]. The incidence of diabetic ketoacidosis due to severe metabolic control in children with $\mathrm{A} 1 \mathrm{c} \geq 9 \%$ has been reported at $13.7 \pm 0.72$ per 100 patients/year [25]. Furthermore, diabetic ketoacidosis is considered a serious issue among children with age of $13.9 \pm 3.1$ years, with one study reporting diabetic acidosis as a reason for hospital readmission [21].

\section{Limitations of study}

There were some limitations in this study. First, these samples may not represent the total population of patients with T1DM in UKMMC. Second, measurement of adherence based on a 1-year visit record using prescription filling through the pharmacy computer system may not reflect the actual prescribing, dispensing, and usage of medications by the patient. Third, the duration of supply was assumed to be the total days of supply, which may overestimate the adherence. Finally, the last A1c measurement obtained during the study period may not accurately represent adherence to insulin treatment provided that the patient has not achieved optimal glucose control yet. Despite these setbacks, the findings from this study may be utilized to develop educational materials to improve adherence and patients' quality of life as seen in other studies on adult patients with Type 2 diabetes $[27,28]$.

\section{CONCLUSION}

Adherence to insulin treatment among children with T1DM at UKMMC was poor, with only three patients adhering to insulin treatment based on A1c measurement. MPR measured using patient visitation records overestimated adherence. In this study, no predictors were significant predictors of adherence, based on the multiple logistic regression analysis. Further research should be performed prospectively in this area to identify reasons for non-adherence to insulin treatment so that appropriate interventions can be instituted to improve adherence and ultimately prevent complications from the disease.

\section{ACKNOWLEDGMENTS}

The authors would like to thank the pharmacy staff at the UKMMC for access to the pharmacy's computerized dispensing database. The authors would also like to thank the hospital medical records staff for their help in retrieving the medical records.

\section{REFERENCES}

1. International Diabetes Federation. IDF Diabetes. $2^{\text {nd }}$ ed. Brussels, Belgium: International Diabetes Federation; 2015. Available from: http://www.diabetesatlas.org.

2. Craig ME, Jones TW, Silink M, Ping YJ. Diabetes care, glycemic control, and complications in children with Type 1 diabetes from Asia and the Western pacific region. J Diabetes Complications 2007;21(5):280-7.

3. Walker T. For children, skipped medications often lead to emergency department visits. Formulary 2013;48:313.

4. Schwartz DD, Cline VD, Hansen JA, Axelrad ME, Anderson BJ. Early risk factors for non-adherence in paediatric Type 1 diabetes: A review of the recent literature. Curr Diabetes Rev 2010;6(3):167-83.

5. Chang $\mathrm{CW}$, Yeh $\mathrm{CH}$, Lo FS, Shih YL. Adherence behaviours in Taiwanese children and adolescents with Type 1 diabetes mellitus. J Clin Nurs 2007;16(7B):207-14.

6. Chisholm V, Atkinson L, Donaldson C, Noyes K, Payne A, Kelnar C. Predictors of treatment adherence in young children with Type 1 diabetes. J Adv Nurs 2007;57(5):482-93.

7. Brown MT, Bussell JK. Medication adherence: WHO cares? Mayo Clin Proc 2011;86(4):304-14

8. Tan SM, Shafiee Z, Wu LL, Rizal AM, Rey JM. Factors associated with control of Type 1 diabetes in Malaysian adolescents and young adults. Int J Psychiatry Med 2005;35(2):123-36.

9. Faiman K, Motheral B. Evaluating medication adherence: Which measure is right for your program? J Manag Care Pharm 2000;6(6):499-504.

10. Donnelly LA, Morris AD, Evans JM; DARTS/MEMO collaboration. Adherence to insulin and its association with glycaemic control in patients with Type 2 diabetes. QJM 2007;100(6):345-50.

11. Ismail HI, Ng HP, Thomas T. Paediatric Protocols for Malaysian Hospitals. $3^{\text {rd }}$ ed. Malaysia: Ministry ofHealth;2013.p. 245-53. Available from: http://www.mpaweb.org.my/file_dir/6549703650eae1487f6fb. pdf. [Last accessed on 2016 Aug 24].

12. American Diabetes Association; 2014. Diabetes association sets new A1c target for children with Type 1 diabetes. Available from: http://www.diabetes.org/newsroom/press-releases/2014/diabetesassociation-sets-new-a1 c-target-for-children-with-type1-diabetes.html. [Last accessed on 2014 Dec 01].

13. De las Cuevas C. Towards a clarification of terminology in medicine taking behaviour: Compliance, adherence and concordance are related although different terms with different uses. Curr Clin Pharmacol 2011;6(2):74-7.

14. Hood KK, Peterson CM, Rohan JM, Drotar D. Association between adherence and glycaemic control in paediatric Type 1 diabetes: A metaanalysis. Pediatrics 2009;124(6):e1171-9.

15. Hilliard ME, Wu YP, Rausch J, Dolan LM, Hood KK. Predictors of deteriorations in diabetes management and control in adolescents with Type 1 diabetes. J Adolesc Health 2013;52(1):28-34.

16. Laxmisan A, Vaughan-Sarrazin M, Cram P. Repeated haemoglobin A1c ordering in the VA health system. Am J Med 2011;124(4):342-9.

17. Sacks DB, John WG. Interpretation of haemoglobin A1c values. JAMA 2014;311(22):2271-2. 
18. Vink NM, Klungel OH, Stolk RP, Denig P. Comparison of various measures for assessing medication refill adherence using prescription data. Pharmacoepidemiol Drug Saf 2009;18(2):159-65.

19. Grey M, Davidson M, Boland EA, Tamborlane WV. Clinical and psychosocial factors associated with achievement of treatment goals in adolescents with diabetes mellitus. J Adolesc Health 2001;28(5):377-85.

20. Davis CL, Delamater AM, Shaw KH, La Greca AM, Eidson MS, Perez-Rodriguez JE, et al. Parenting styles, regimen adherence, and glycaemic control in 4-to 10-year-old children with diabetes. J Pediatr Psychol 2000;26(2):123-9.

21. Lim PK, Chia YY, Lek N, Haas L, Maryniuk M, Beck J, et al. Paediatric hospital readmissions with diabetes mellitus. Singapore Nurs J 2012;39(4):23-8

22. Borus JS, Laffel L. Adherence challenges in the management of Type 1 diabetes in adolescents: Prevention and intervention. Curr Opin Paediatr 2010;22(4):405-11.

23. Krapek K, King K, Warren SS, George KG, Caputo DA, Mihelich K, et al. Medication adherence and association haemoglobin A1c in Type 2

\section{APPENDIX}

Appendix Table 1: Interpretation of kappa values

\begin{tabular}{ll}
\hline Kappa value & Interpretation \\
\hline$<0$ & Poor agreement \\
$0.0-0.20$ & Slight agreement \\
$0.21-0.40$ & Fair agreement \\
$0.41-0.60$ & Moderate agreement \\
$0.61-0.80$ & Substantial agreement \\
$0.81-1.00$ & Almost perfect agreement \\
\hline
\end{tabular}

Sources: Landis and Koch, 1977 [26] diabetes. Ann Pharmacother 2004;38(9):1357-62.

24. Stewart C, Brown L, Poirier M. Guidelines for the management of paediatric diabetic ketoacidosis (DKA). Paediatr Emerg Med Pract 2006;3(3):1-16.

25. Karges B, Kapellen T, Neu A, Hofer SE, Rohrer T, Rosenbauer J, et al. Long-acting insulin analogs and the risk of diabetic ketoacidosis in children and adolescents with Type 1 diabetes: A prospective study of 10,682 patients from 271 institutions. Diabetes Care 2010;33(5):1031-3.

26. Landis JR, Koch GG. The measurement of observer agreement for categorical data. Biometrics 1997;33(1):159-74

27. Asmini P. The influence of education of drug information by pharmacist on the improvement of knowledge and therapeutic target to Type 2 diabetes mellitus outpatients in hospital. Int J Pharm Pharm Sci 2017;9(3):199-204.

28. Balaiah S, Tirupa M, Narayana G, Mohanraj R, Reddy YP. Assessment of pharmaceutical care services on health related QOL in patients with Type 2 diabetes mellitus - A prospective interventional study. Int $\mathrm{J}$ Pharm Pharm Sci 2014;6(7):456-61. 